PART I

Emotion and the Nature of Value 



\title{
2 \\ In What Sense Are Emotions Evaluations?
}

\author{
Julien A. Deonna and Fabrice Teroni
}

\section{Introduction}

Why think that emotions are ways of evaluating? This chapter puts forward an original account of emotions as evaluations apt to circumvent some of the chief difficulties with which alternative approaches find themselves confronted. We shall proceed by first introducing the idea that emotions are evaluations (sec. I). Next, two well-known approaches attempting to account for this idea in terms of attitudes that are in and of themselves unemotional but are alleged to become emotional when directed towards evaluative contents are explored. According to the first approach, emotions are nothing but evaluative judgments. Sec. II reminds the reader of the problems associated with this idea: one of its consequences is to deprive creatures with limited cognitive capacities of any sort of partaking of emotional life. According to the second approach, which is often praised for its capacity to avoid the pitfalls facing an appeal to evaluative judgments, emotions are perception-like experiences of evaluative properties and are as such within the reach of creatures bereft of conceptual capacities. This perceptual theory is taken up in sect. III, in which we explain why it remains unsatisfactory insofar as it shares with the evaluative judgment theory the idea that what makes emotions evaluations is the specific contents that they have. On this basis, we proceed by outlining in sect. IV an alternative-the attitudinal theory of emotions. Its main point of departure from current theorizing about the emotions consists in elucidating the fact that emotions are evaluations not in terms of what they represent, but rather in terms of the sort of attitude subjects take towards what they represent. We explore here what sorts of attitudes emotions are and defend the idea that they are felt bodily attitudes.

\section{Emotion as Access to Value}

Why is the idea that emotions are apprehensions of values so attractive? Ordinary language certainly vouchsafes for the existence of a close connection between emotions 
and values. Several evaluative words thus appear to derive from words referring to types of emotions: we speak of the disgusting, the amusing, the regretful, the admirable, the shameful, and so forth. ${ }^{1}$ These linguistic data constitute some suggestive evidence in favour of the idea that emotions relate to values. Still, what does this mean exactly? The answer requires that we have at least a working characterization of the notion of value at stake as well as a preliminary understanding of how values relate to emotions. Let us consider these issues in turn.

The idea we are trying to capture appeals to values in a way that, although not strictly technical, diverges from that in which it is used in ordinary language. People typically talk of values in connection with abstract ideals driving their lives. It is in this sense that friendship and solidarity may be thought of as paradigmatic values. These, however, are not the sort of entities that we are concerned with here; by "value," we rather designate a specific type of property which may be instantiated by objects, events, or situations. From this viewpoint, a joke exemplifies the value of being amusing or humorous, the disappearance of a loved one, that of constituting a loss, and so on. The idea is thus that emotions relate to exemplifications of properties of this type, and not to abstract ideals. Moreover, as some of the previous examples suggest, the evaluative properties at issue are, by contrast with abstract ideals, susceptible of being either positive (the amusing, the admirable) or negative (the shameful, the disgusting).

Let us now try to provide a preliminary understanding of the manner in which emotions relate to these evaluative properties. Imagine a subject finding herself on a hunting expedition. Sight and hearing allow her to apprehend an indistinct form only a few yards away and the sound of heavy breathing, while the testimony of the gamekeeper allows her to apprehend that she is about to be attacked by a wild boar. The core idea shared by the approaches according to which there is an intimate connection between emotions and values is captured by the idea that one can pursue the enumeration just laid down as follows: and fear allows the subject to apprehend the boar's dangerousness. More generally, the idea is that there is an intentional relation between one's emotions and the values exemplified by the objects and events one may confront: different types of emotions are apprehensions of distinct values. Thus, fright will be the apprehension of the dangerous, anger the apprehension of the offensive, amusement the apprehension of the comical, and so forth.

The foregoing has, we hope, conveyed the sort of intuitive appeal that an approach emphasizing the existence of a relation between emotions and values may claim. What about its theoretical virtues? Let us begin by observing that the approach is able to give convincing answers to some of the fundamental questions facing any theory of the emotions. Indeed, its friends are likely to insist that appealing to values allows for the individuation, rationalization, and assessment of emotions (see e.g. Teroni 2007).

\footnotetext{
${ }^{1}$ This point is aptly emphasized by Mulligan (1998) and Tappolet (2000). A typology of emotions based on their connection to values is illuminatingly laid out by Roberts (2003).
} 
First, values have the potential to individuate emotion types insofar as they constitute something that is shared by the various objects of a given emotion type. Although different episodes of sadness may be related to particular objects as disparate as the disappearance of a loved one, failure at an exam, the melting of a glacier, and so on, the subject who feels sad nevertheless apprehends all these objects as losses. This is to say that emotion types are unified at the level of their evaluative intentionality, and that we can distinguish them by means of the distinct values to which they relate.

Second, an appeal to values allows for measuring whether or not emotions are rational or intelligible. Observe that we understand how very different situations can elicit emotions of the same type once we realize that, from the subject's point of view, they each exemplify the same evaluative property. This being the case, a given emotion becomes intelligible once we figure out how such a point of view may have been fostered by the circumstances ("After all, reaching out to him might have been understood as an offense and might thus have made him angry"); otherwise it remains unintelligible.

Finally, values play an essential role in the way we assess emotions. After all, we are naturally inclined-and for good reasons! - to treat some emotional episodes as appropriate, others as inappropriate. Within the present framework, this contrast is primarily to be understood in terms of the opposition between emotions directed at objects or situations that do exemplify the relevant values, and emotions directed at objects or situations that do not exemplify them. Insofar as a remark was innocent, for instance, the anger it has triggered is inappropriate. This is why it makes sense to speak of the evaluative conditions of correctness of the emotions-a notion to which we shall return repeatedly in what follows. ${ }^{2}$ The underlying idea consists in approaching the emotions in a way that is routine in philosophical discussions of other types of mental states. A visual experience of a red kite on the roof of the house has specific conditions of correctness (simplifying a bit: the presence of such a kite at that particular location); analogously, an episode of fear directed at the danger represented by a narrow mountain trail has specific evaluative conditions of correctness (the path's dangerousness). In both cases, the representation may turn out to be either correct or incorrect, depending on whether or not the world actually is the way it is represented to be. ${ }^{3}$

Philosophers have in mind precisely these three distinct roles that values may play when they treat them as the formal objects of the emotions-yet another notion to

2 While it is perhaps natural to speak of the emotions as appropriate or inappropriate, we do not ordinarily speak of them as correct or incorrect. The latter are terms of art, then, and correspond to the sort of epistemic assessment to which the emotions are subject, as opposed to other ways (prudential, moral, and so on) in which they might also be assessed (see D'Arms and Jacobson 2000).

${ }^{3}$ Let us observe that, if the idea of evaluative conditions of correctness invoked here is incompatible with strong subjectivism about evaluative properties, it is perfectly compatible with quite a wide range of alternative ontological claims (such as sophisticated dispositionalist accounts as well as fitting-attitudes and realist accounts). 
which we shall return in what follows. ${ }^{4}$ However, in order to account for this as well as for many other fundamental claims regarding the emotions, we need first of all to get a firmer grip on a notion central to the previous observations: that of a "way of apprehending value."

\section{The Evaluative Judgment Theory}

We are all familiar with the distinction between attitude and content. ${ }^{5}$ Mary may for instance either believe that it is raining or believe that the weather is nice; that is, she may have the same attitude towards two different contents. It is of course also possible to have two different attitudes towards the same content: Mary comes to believe that the weather is nice after having looked out of the window, whereas Jean, who has not opened the blinds yet, desires that to be the case. It is natural to approach the emotions in terms of that same contrast. After all, not only can we believe or desire that it rains, we can also hope, fear, or regret it. Natural as it may be, this idea has not been pursued at all within recent philosophical approaches to the emotions. This is to say that, instead of trying to see where the idea that emotions are distinctive sorts of attitudes might lead, the general trend has consisted in trying to account for the emotions in terms of this or that already familiar attitude and, correlatively, to leave to their specific contents the task of accounting for what is emotional about them.

This is especially manifest in a conception that was already advocated in antiquity, according to which emotions relate to values because they consist in evaluative occurrent beliefs or judgments. Types of emotions are then distinguished from one another in terms of the different value attributions that feature in the contents of these judgments. ${ }^{6}$ Thus, judging that one is in a dangerous situation is to be afraid of it, judging that one has committed a fault is to feel guilty about it, and so on. This approach not only allows for the individuation of emotions by means of the evaluative concepts deployed in the relevant judgments, it can also draw the needed distinctions between intelligible, unintelligible, appropriate, and inappropriate emotions-it of course recommends to understand these two contrasts in the light of whatever constraints bear

\footnotetext{
${ }_{4}$ Kenny (1963) introduces the idea of formal object into the contemporary debate. The various roles formal objects may play in connection to the emotions are discussed in Teroni (2007). For skepticism about this idea, see Deigh (1994).

5 Henceforth, we shall use "attitude" where others use "mode." The choice is governed by the idea that thinking of the different emotions as different attitudes we take towards the world is, as we shall argue, just right. Being typically used within the expression "propositional attitude," however, it has the drawback of encouraging the claim, which we shall reject, that emotions are attitudes exclusively directed at propositions. This drawback is largely compensated, we believe, by the benefits of avoiding any confusion that might arise between the idea of "mode" and that of "modes of presentation." The latter, which has to do with distinctions amongst contents, will play no role in what is to come.

6 This theory, which is often said to have been defended by the Stoics, was brought back into fashion by Nussbaum (1994) and Solomon (1988).
} 
on the intelligibility and appropriateness of the evaluative judgments at issue. As is widely acknowledged, however, conceiving of emotions as judgment-like attitudes directed towards evaluative contents is hardly satisfactory. Revisiting some of the difficulties from the vantage point offered by the attitude vs. content contrast will provide important clues on the way to a satisfactory account.

First, the proposed analysis simply does not lay out sufficient conditions for having an emotion. It is quite common for a subject to make an evaluative judgment without thereby being emotionally affected in the way she would have to be if the proposal were along the right track. It is not, since judging that it is dangerous to live in Tokyo is obviously quite different from being afraid of living there. In addition, the theory cannot account for the fact that emotions may sometimes be caused by evaluative judgments ("Max was frightened because he had judged the situation to be dangerous"); for this cannot be reconciled with the purported equivalence between the two. All this is illustrative of a more general point: the theory cannot do justice to the phenomenological aspect of emotions-a point we shall return to.

Second, if we think that young infants and animals are capable of feeling emotions, it is then difficult to maintain that this requires the making of evaluative judgments. For the capacity to make judgments of this nature may be exclusive to humans who have reached a certain stage of their cognitive development (e.g. Deigh 1994; Tappolet 2000). Let us briefly rehearse why this may be thought to be the case. According to many, the attitude of judging, regardless of how precisely we spell that out, amounts to asserting a propositional content or, to put it in slightly different words, to committing oneself to the truth of a given proposition. If this is the case, then judging requires, on the one hand, the capacity to think a proposition and, on the other hand, the capacity to commit oneself to its truth. To judge that the weather is nice thus requires the capacity to think that the weather is nice together with the capacity to endorse this as a fact. It is legitimate to doubt that animals and young infants are really capable of such cognitive prowess. After all, to commit oneself to the truth of a proposition seems to require, if not the general capacity to weigh the reasons bearing on judgments, at least the capacity to refrain making such judgments when circumstances require. And such capacities do seem to be a human prerogative. This is one reason why one may want to resist appealing to judgments in trying to understand emotions.

We may be running ahead of ourselves, however. Perhaps the evaluative judgment theory faces these difficulties chiefly because it misdiagnoses the exact nature of emotional attitudes-judging may simply be a near miss. There are indeed popular approaches that are closely related to the judgment theory but which deny that subjects must commit to the truth of the relevant proposition. And, for all we have said so far, those might very well fit the bill. If so, what sort of attitude would do the trick? Patricia Greenspan sets her sights on the attitude of entertaining a proposition; Robert Roberts sails in the same waters when he argues that the desired attitude is that of construing certain facts in the light of a given value (Mary can thus construe a dog as dangerous 
without thereby asserting that it is such). ${ }^{7}$ It stands to reason that this strategy allows for a more satisfying treatment of a certain range of cases. For example, one may then treat the situation in which, say, a subject judges that a given object is not dangerous while being nevertheless afraid of it without having to invoke a severe form of irrationality. He no longer needs to be understood as making contradictory judgments; he may much more plausibly be said to judge that the object does not exemplify a given value while still construing it in terms of that same value (Roberts 2003: 89-93).

That being said, this change of attitude within the framework set by the evaluative judgment theory does not really succeed in solving the problem. After all, the requirement that the subject must be capable of having the relevant proposition in mind when undergoing the emotion remains in full force. And creatures with limited cognitive capacities may well prove unable to achieve that much, regardless of any difficulty associated with the additional requirement that one is committed to its truth. ${ }^{8} \mathrm{~A}$ proposition, as it is generally understood within the relevant literature, is an articulated sequence of concepts that is truth-assessable. As a consequence, to have a proposition in mind requires the capacity to deploy the concepts which constitute it. ${ }^{9}$ Someone cannot, for instance, believe that one's husband plays the bagpipe without having the concepts of "husband" and of "bagpipe." Furthermore, given what is involved in mastering and deploying concepts, the capacity in question is cognitively quite demanding. Mastery of a concept seems in fact to require of a subject that she master at least some of the epistemic, semantic, and logical relations tying the concept in question to other concepts. ${ }^{10} \mathrm{~A}$ subject who masters the concept of red, for instance, must first be capable of distinguishing the circumstances in which its application is justified from those in which it is not. This is made manifest, for instance, in her attentiveness to varying conditions of illumination that may potentially defeat her color judgments. Moreover, such a subject must display an understanding of some of the relations the concept in question bears to other concepts like, say, the concept of color (what is red cannot be green; what is red is colored) and that of a surface. This explains several aspects of the normativity and rationality of conceptual states; it underscores, for instance, the idea that a subject who makes a given judgment must either accept its logical and epistemic implications, or otherwise agree to revise it once she becomes aware of the difficulties it raises. Conceptual thinking is thus cognitively

\footnotetext{
7 See Greenspan (1988) and Roberts (1988, 2003: 92). Roberts emphasizes the fact that the attitude specific to emotions does not involve an assertion of the content. He attempts a positive characterization of the emotional attitude as one in which the subject views its content as having the "appearance of truth."

${ }^{8}$ Roberts insists on the fact that the open variable in "construe $a$ as $\mathrm{x}$ " can in principle be occupied by any type of representation (images, concepts, or even perceived objects). Where values are concerned, however, "construing $a$ as x" must entail a subject deploying her conceptual capacities. While Roberts advertises his theory as a perceptual one, the point just stressed motivates its inclusion in the present section.

9 It is true that the expression "propositional content" is sometimes used to merely mean something like truth-assessable content, and this may lead one to perceive our emphasis on concept-deployment as misplaced. Yet, the near consensus within the present literature regarding the conceptual nature of the content of judgment and judgment-like attitudes warrants the more substantial characterization of propositional content we work with in our presentation.

10 This way of developing the idea of conceptual content is that of Crane (1992). Bermudez (1998) offers an alternative account, which is criticized in Creese and Deonna (2006).
} 
much more demanding than the capacity to respond discriminatively to various stimuli, a capacity which is widely, if not universally shared by animals.

Now, if these observations are met with approval when they concern colors, they must $a$ fortiori be accepted as regards the evaluative concepts appealed to by the theories under examination. The strategy consisting in modifying slightly the evaluative judgment theory by allowing that a subject undergoing an emotion need not accept the truth of the relevant proposition is then clearly unsuccessful. The fundamental worry stems from the fact that emotions are conceived of as mental states dependent on capacities similar to the ones we deploy when we commit ourselves to the truth of a proposition. And this, together with its failure to accommodate the experiential dimension of emotions, is more than enough to reject the evaluative judgment theory and its variants. The considerations we brought to bear on this rejection also constitute one of the chief reasons why it is nowadays widely accepted that, if emotions are ways of apprehending values, this should be understood in completely different terms. This is precisely the purpose of the so-called perceptual theory of emotions.

\section{The Perceptual Model}

The conclusion to which we have been led is that the evaluative judgment theory and its variants fail to provide a plausible account of how emotions relate to evaluative properties as well as for the fact that they are experiences with a salient phenomenology. It has provided the incentive to pursue an alternative approach that consists in trying to understand emotions on the model of perceptual experiences. ${ }^{11}$ In a nutshell, the core idea is now that emotions must be understood as perception-like experiences of values rather than as evaluative judgments or thoughts.

This is unquestionably an attractive move. Perceptual and emotional experiences have both intentional as well as phenomenological aspects. If a theory of the emotions must unify these two aspects in some convincing manner, it is then tempting to appeal to perceptual experiences in order to account for the felt aspect of emotions. All the more so since such a perceptual approach has the merit of getting around the two chief difficulties concerning respectively the attitude and the content of emotions that we have expanded on at some length while discussing the evaluative judgment theory. Let us consider them in turn.

The attitude involved in perceiving has often been claimed to be distinct from that of judging, and this for reasons identical to those adduced in the preceding section with regard to the emotions. ${ }^{12}$ Our judgments about the properties of our surroundings are

\footnotetext{
${ }^{11}$ This model, anticipated by de Sousa (1987), is explored in detail and espoused by Tappolet (200o, forthcoming) and defended in different versions by Döring (2007, 2008), Prinz (2004), Deonna (2006), as well as Deonna and Teroni (2008). As will become obvious, we have since then changed our minds.

${ }_{12}$ An influential paper developing this claim is Crane (1992). Perhaps because many are convinced that perceiving is not an attitude or a mode, positive characterizations of perceiving as an attitude or a mode are scarce. For some insightful remarks on this topic, see Mulligan (1999) and Sturgeon (2000: ch. 1).
} 
sometimes at odds with the deliverances of our senses (as the fabled straight stick half immersed in water illustrates), and such situations are just as commonplace as those in which our evaluative judgments and affective responses vis-à-vis a given object or situation come apart. Michael is fully aware of the fact that this small bug is hardly dangerous; yet, he shivers at its sight and swears that he is about to die. More generally, there exists a variety of emotional illusions, amongst which there are phobias-illusions of a particularly acute and recurrent nature. Regarding such cases, the perceptual model has a clear advantage over the judgment theory: namely, that of acknowledging the existence of such conflicts without thereby implying that the conflicted subjects are affected by a serious form of irrationality. ${ }^{13}$ It can claim this theoretical advantage because the sort of attitude that is characteristic of perception differs crucially from that of judging. ${ }^{14}$ Of course, we have seen that some variants of the evaluative judgment theory can lay claim to the same advantage, but the perceptual model has the additional merit of doing this without requiring that the subject possess complex cognitive capacities. Let us now turn to this last consideration as it constitutes one of the key promises of the perceptual model.

That model indeed turns out to be equally attractive when attention is turned to the content of emotions: perceptual and emotional experiences arguably constitute two examples of mental states endowed with non-conceptual content. By this, reference is made to experiences that are contentful - that is, represent something-without this depending on the subjects' deployment (in the sense specified previously) of the concepts used to specify these contents. The idea is thus to sever issues related to representation from issues related to concept mastery. And it can be profitably applied to the kinds of experiences we are considering. Creatures with limited or no conceptual abilities may perfectly well perceive a given shade of red, or feel a particular danger, without thereby being able to meet the various requirements connected to judgments of color or value. Although space does not permit us to examine in much detail the different arguments in support of this idea, we shall at least briefly rehearse a few considerations that have been put forward in its favor.

Observe first that perceptual experiences seem to be free from the epistemic and normative constraints associated with conceptual thinking; more specifically, they are not subject to norms. As opposed to passing a judgment about it, perceiving a given property or object does not depend on the mastery of the kinds of epistemic, semantic, and logical relations tying the concept in question to other concepts laid

\footnotetext{
${ }_{13}$ This issue has been the focus of an interesting debate whose main protagonists are Brady $(2007,2009)$, Döring (2008, this volume), Helm (2001), Roberts (2003), and Tappolet (2000, 2012).

${ }_{14}$ This way of distinguishing the emotional attitude from the judgment it may give rise to makes room for the possibility of developing within the perceptual approach an epistemology of values that assigns to emotions a role similar to that of perceptions. The idea is that while visual or auditory perceptions can justify judgments about visual or auditory properties, emotions play the same role as regards evaluative judgments. We shall not address these important epistemic questions here. For a detailed treatment of the relevant issues, see Deonna and Teroni (2012: chs. 8-10).
} 
out in the foregoing. This contrast at the level of content explains why the fundamental norms bearing on judgments do not bear on perception. Thus, for instance, while we are bound to accept the logical consequences of our judgments, there are no other perceptual experiences which we should have as a result of perceiving, say, the redness of a tomato. Indeed, the very notion of such a constraint barely makes sense. Second, the fineness of grain which characterizes perceptual experiences darkens the prospects of assimilating them to conceptual states. We never perceive properties such as red, or crimson, but much more specific shades that we cannot conceptualize any more than we can retain them in short-term memory. In a nutshell, the fineness of grain of perceptual experiences exceeds our conceptual capacities. Finally, it is often said that the acquisition of many of our concepts has its roots in perception, and this could not be the case if perceiving any property required that one deploy the relevant concept. ${ }^{15}$

According to the advocates of the perceptual model, the three types of consideration just reviewed apply equally to the emotions: they are similarly free of the constraints associated with the presence of concepts, they likewise respond discriminatively to very subtle evaluative differences (that we could not easily articulate conceptually), and they play a crucial role in the acquisition of evaluative concepts such as those of danger, offense, disgrace, and so forth. Because the aforementioned cognitive constraints do not bear on experiences with non-conceptual content, a perceptual theory has a real edge over its older cousin. ${ }^{16}$

Similarities between perceptual and emotional experiences can thus be found at the level of attitude as well as at the level of content. So, why not endorse the substantial claim according to which emotions literally are perceptions of values? As a matter of fact, this claim becomes hard to maintain as soon as attention fixes on some key differences between emotions and perceptual experiences. We shall mention here only a few. First of all, some will argue that perceptual experiences are underpinned by the activities of various sense organs, whereas this idea does not make much sense in the case of emotions. Second, emotions lend themselves naturally to being classified according to their polarity or valence (e.g. Colombetti 2005; Teroni 2011): some of them are negative (fear, sadness, shame), others are positive (joy, pride, admiration). Yet, such a classification makes no sense for perceptual experiences. Finally, while perception provides us with information about our environment through mechanisms that are relatively impervious to our motivational states, ${ }^{17}$ emotions, by contrast, are highly responsive

${ }^{15}$ Of course, the debate between conceptualists and non-conceptualists has left philosophers of perception divided. For positions that reject the approach articulated here-that is, conceptualist positions-see, for example, McDowell (1994) and Brewer (2002).

${ }^{16}$ Tappolet (forthcoming) elaborates the claim that emotions have non-conceptual content, whereas Helm (2001) emphasizes the existence of strong normative constraints bearing on affective states.

${ }_{17}$ This claim presupposes that we carefully distinguish perceptual states from both attention and perceptual judgments, as the latter are, of course, influenced by our motivational states. On this point see, in particular, Dretske (2006). 
to our desires, concerns, and character traits. Now, it is certainly possible to wonder whether these differences really threaten the import of the analogy between emotion and perception. They may, after all, not run very deep, and we should perhaps learn to live with them in the light of the significant advantages delivered by the perceptual approach. So let us turn our attention to two further differences that cannot be welcomed with such equanimity.

The first one regards the realm of things about which we can have emotions. This realm is definitively not circumscribed in the way the realm of perceptual objects is. In order for someone to be in a position to, for instance, see an object, several constraints must be fulfilled: the object cannot be abstract, the subject must be in a given spatial relation to it, certain lighting conditions must obtain, the field of view must be unobstructed, some physical processes must take place, and so forth. No object can be seen unless these conditions are met. Things are quite different with the emotions. If Sam is afraid of the racoon right in front of him, then conditions identical to those holding for perception must surely be met for his fear to be about the racoon. Yet although emotions grounded in perceptual experiences are perhaps paradigmatic cases, many others are about situations that are remembered, imagined, believed, supposed, and so on. Furthermore, there can be emotions about abstract objects just as there can be emotions about concrete ones-Maria may regret the lack of justice in her country, and Michelle may hope that Darwinism is true. So, while the set of the possible objects of emotions is entirely open, this fails to carry over to the case of perception. This puts the perceptual model under substantial pressure. Indeed, one fundamental issue at this stage is whether someone may properly be said to be in a perceptual relation with the evaluative property of an object she happens to represent in a memory, a belief, a supposition, or an imaginative state. A positive answer to this is perhaps not inconceivable, ${ }^{18}$ but definitively not very promising. More generally, the previous considerations should make one wonder whether there is any plausibility in the claim that the relation between emotions and values is of a perceptual nature. Many would object that values are simply not the sort of properties one could possibly perceive. However that may be, in order to account for the relation between emotions and values, the theory appears to do no more than postulate the existence of a perceptual relation whose nature remains ultimately unexplained. As we shall see, a significant advantage of the alternative theory we are about to put forward consists precisely in its capacity to elucidate the relation in question.

The second difference between perceptions and emotions, which is closely related to what we have just said, is perhaps even more significant. Perception constitutes an autonomous way of accessing the properties and objects it represents: seeing, hearing, or touching do not latch onto some prior apprehension of the properties or objects

${ }^{18}$ It might indeed become conceivable if, following Pelser (this volume), one conceives of the content of perception as being fully propositional in the substantial sense retained in the present chapter. As we have argued, it is unclear to us how this constitutes an improvement on the judgment theory of emotions. 
they give access to. In order for a subject to be in a position to see the redness of a tomato, or hear the pitch of a given voice, no prior access to such properties needs to be secured. Emotions work differently. They latch onto other psychological states, which, as we have seen, may be of many distinct types (beliefs, memories, imaginative or perceptual experiences), and which function as their cognitive bases. In order for one to be afraid of a dog, one needs some representation of the dog that is logically prior to the emotion itself: one needs to see, hear, or have beliefs about it. This difference is of the utmost importance. ${ }^{19}$ Indeed, one of the main tasks with which a theory of the emotions is confronted consists in offering a satisfactory explanation of the relation between emotions and their cognitive bases. To emphasize just one lesson among several which may be drawn from the fact that emotions can have a great variety of objects, it is now clear that we should challenge the assimilation of emotions to states susceptible of having only one type of content-a conceptual proposition-like content according to the evaluative judgment theory or a non-conceptual one according to the perceptual theory. An alternative to these must be found.

The journey accomplished so far has led to the following conclusion. Although fruitful in some respects, the analogy between emotion and perception, if pushed too far, obscures some fundamental differences between the two types of mental states. Two different strategies may now be envisioned. The first one consists in forsaking any straight identification of the emotions with perceptions of values while pursuing the kindred approach consisting in claiming that emotions, while not strictly perceptions, are still experiences of values. We shall not discuss this strategy here, for we incline to think that its various forms do not improve our understanding of the emotions. ${ }^{20}$ The second, more radical strategy consists in preserving the idea that emotions relate to values while rejecting a claim shared by the judgment theory and the perceptual theory; namely, that values are represented by the emotions. The remainder of this chapter is devoted to a brief presentation of this strategy.

\section{The Attitudinal Theory}

We have seen that attempts to capture the specific relation that takes place between emotions and values in terms of judgment-like or perception-like attitudes are likely

\footnotetext{
19 We are familiar with the idea that perception is cognitively penetrable; that is, that some features of its content can depend on the fact that the subject possesses given conceptual abilities. This sense in which perception may be said to have cognitive bases has nothing to do with the kind of dependence we are referring to here; that is with the fact that emotions inherit their contents, whatever these contents are, from other mental states.

${ }^{20}$ If reference to perception is simply meant to draw attention to just one or another feature shared by perceptual and emotional experiences-be it a salient phenomenology, the presence of non-conceptual contents, modularity or near modularity, appearance of truth, or the capacity to justify the relevant judgments non-inferentially or anything else-then it would be better to do without such a misleading reference and simply account for these features of emotions. For a detailed presentation and criticism of both the literal and the more relaxed perceptual approaches to the emotions, see Deonna and Teroni (2012: ch. 6).
} 
to fail. Now, the central source of the problems they confront is the fact that these approaches proceed by redeploying attitudes that have nothing emotional about them but that are alleged to somehow turn into emotions when they relate to specific evaluative contents. Provided that these theories share the distinctive claim that emotions put the subject in relation to values because they represent such properties, we have an incentive to put this claim into question. That is to say that the difference between emotions and other types of attitudes, as well as the difference between types of emotions-at least insofar as their relation to evaluative properties is concerned-is not to be located at the level of content, but at the level of the attitudes themselves. Although sibylline at this stage, such an alternative approach has at least an intuitive ring about it.

Conceiving of the different types of emotions as many different attitudes rather than one and the same attitude - that of judging, that of perceiving, or, for that matter, that of emoting ${ }^{21}$ - directed at the representation of different evaluative properties should after all appear as plain common sense. Is it not obvious that the contrast between, say, fear, anger, and joy is to be understood as one between different attitudes we take towards objects, events, situations, and so forth? Is this contrast not to be located at the same level as the contrast between, say, desiring, believing, and conjecturing-and is it not at the same time to be carefully distinguished from the contrast between believing a given proposition and believing a different one? We think that these two questions should be answered affirmatively. To locate such a relation at the level of the attitude has the additional virtue that it stands in basic agreement with the intuitive idea that two distinct emotions can literally have the same content. After all, if Maria is amused by a remark which irritates Michelle, it is natural to think that they are adopting different attitudes regarding one and the same content. ${ }^{22}$ This cannot be maintained within a perceptual model, however, within which to be amused by something consists in perceiving its humorous character, whereas to be angry at it consists in perceiving its offensiveness.

Still, as intuitive as such an attitudinal approach to the relation between emotions and values may be, we should not come to a verdict before having turned our attention to the following issues. What is the nature of emotional attitudes? In what sense are they evaluations? To deal with these questions, we shall first briefly retrace our steps to what we have observed, and shall on this basis articulate and defend the idea that emotional attitudes are distinctive types of bodily attitudes. Second, we shall move on to explain why this attitudinal theory is apt to illuminate the sense in which emotions are evaluations.

${ }^{21}$ Observe that positing the existence of a generic and sui generis attitude of emoting that would be shared by all different types of emotion would, in the present context, constitute a clear step backwards, for it would once again require that the differences among these types be made at the level of content. In the light of the foregoing, this is not the strategy to pursue. The idea that emotions are attitudes in the sense of types of position-taking is nicely emphasized in De Sousa (1987).

${ }^{22}$ Goldie (2004) and Gunther (2004) object to the idea that in emotion a clear demarcation line between attitude and content can be drawn in this way. The weaknesses of their respective criticisms are exposed convincingly in Herzberg (2012) and in Deonna and Teroni (forthcoming). 
Emotional attitudes, we have already observed, are attitudes that subjects can take towards a variety of different contents. This is because they always inherit their content from that of other mental states that function as their cognitive bases. One may, on the basis of a conjecture to that effect, fear that the stock market will crash, but one may also much more simply be afraid of a lion one sees approaching. Emotions are, in addition, attitudes that are characterized by a very salient phenomenology - it plainly feels like something to be afraid, like another thing to be angry, and so on. To say this, however, naturally leads to the following substantial question: how are we to characterize the phenomenology of emotional attitudes?

Although we cannot adequately defend that claim here, the answer must in our opinion appeal to the way one's body feels. Since William James, philosophers and psychologists alike have put emphasis on the vital importance of this aspect of the emotions. We concur with them: neither introspection nor empirical investigation militates for describing what is affective about episodes of fear, sorrow, anger, shame, joy, hope, and so on, otherwise than in terms of the distinctive ways the body feels. ${ }^{23}$ Now, we are aware that classical and more recent endeavors to understand emotions by appealing to their bodily phenomenology have often led to the conclusion, embraced by will or by force, that emotions cannot acquaint us with anything but our own body. This would obviously constitute a step backwards by comparison with the theories considered up till now, which at least make room for the plain fact that emotions are more often than not directed towards something outside the subject's own body. And the issue is perhaps made especially salient within the sort of attitudinal approach we recommend: glossing an episode of fear or sadness by saying that it is an attitude directed towards the subject's own body indeed hardly makes sense. In any case, we shall now see that one does not need to subscribe to such a thesis even if one insists on the bodily nature of emotional phenomenology.

To see why this is the case, we can start with the following observation: the bodily changes involved in emotions are felt by the subject as distinctive attitudes that are (at least typically) directed towards external objects. In other words, while undergoing an emotion, the subject feels herself taking a distinctive bodily attitude towards a certain object. More specifically, there is, in the words of an early and eloquent advocate of this approach, "a consciousness of a form, a 'Gestalt' of multiple organic impressions [...] a consciousness of a global attitude of the organism" (Claparède 1928: 128). In order to understand the nature of emotional attitudes, we then recommend taking exception to the somewhat atomistic approach to bodily feelings which is common in the recent literature, and appealing instead to a type of bodily awareness which is both holistic and directed towards objects beyond the body. This in addition

\footnotetext{
${ }_{23}$ The principal accounts of the emotions inspired by James found in the contemporary literature are those of Damasio (2000) and Prinz (2004). These accounts, like ours, inherit potentially the many problems that have long been associated with James' theory. For responses to these problems and to several others that the presentation of our account will undoubtedly raise, see Deonna and Teroni (2012: ch. 7 , and forthcoming).
} 
lends itself to an appealing development in terms of an aspect of emotions commonly emphasized within contemporary psychology; namely, action readiness. The feeling of an action readiness is in fact a key element in understanding how emotional attitudes are evaluations, which is, you will recall, the second issue we have to confront.

The core idea is the following: we understand why emotions are evaluations once we admit that they relate to values by virtue of being experiences of one's body being ready or poised to act in some specific manner towards a given object or situation. The notion of bodily attitude we appeal to here is intended in quite a broad sense so as to include the tendency to move away, to approach or move towards an object, to submit oneself to it, to focus on it, to have one's attention captured by it, to disengage one's attention from it, or even the tendency to prevent any contact with it. Here are some illustrations of what we have in mind. Whenever one is afraid, one feels one's body readiness to neutralize something; whenever one is angry, one feels one's body readiness to retaliate in some way or another; episodes of shame are characterized by a felt tendency to disappear from the sight of the ones who elicited this emotion; when sad, we feel our body being deprived of the possibility of interacting with the object whose loss has elicited our emotion. These illustrations are meant to emphasize the agential dimension of the feel specific to emotions. And this is key to understanding the sense in which the latter are evaluative attitudes.

This is best appreciated if we step back a little and remind ourselves of some general features of the way the correctness conditions of mental states are fixed. These correctness conditions are the joint upshot of two distinct factors: the content and the attitude. For instance, the proposition that John speaks Swahili may, amongst other attitudes, be the object of a belief or of a supposition. Its truth or mere possibility enters the conditions of correctness of the resulting mental states by virtue of the fact that it is either believed or supposed. Correctness conditions result, then, from the conjunction of a content, identical in both cases, and distinct attitudes which contribute a property that the proposition featuring in the content must possess-truth in one case, possibility in the other one-for the state to be correct. This is the sense in which belief and supposition relate to truth and possibility, and this has nothing to do with what they represent. We believe that types of emotions relate to types of values, which are their formal objects, in exactly the same way-fear to dangerousness, anger to offensiveness, and so on. The sense in which emotions are evaluative attitudes, then, is this: the fact that they are the very attitudes they are explains why adopting them towards an object is correct if, and only if, that object actually exemplifies the relevant evaluative property.

Thinking of these attitudes in terms of felt action readiness provides an elucidation of why they can play this explanatory role. Fear relates to danger insofar as it is an experience of one's body's readiness to reduce an object's impact (flight, preventive attack, immobility, and so on) - an attitude which is correct to adopt only if the object is actually dangerous. Analogously, anger relates to offensiveness insofar as it is an experience of one's body readiness to retaliate in some way or another, an attitude which is 
correct to adopt only when confronting an offense. And shame relates to one's own degradation insofar as one feels one's body's readiness to disappear into the ground, or to move away from the sight of relevant others - an attitude which is only correct if we are actually degraded. These examples should suffice to illustrate the sense in which emotions are evaluative attitudes. Its fruitfulness depends of course on the possibility of providing rich and convincing descriptions of a substantial amount of emotion types in terms of felt bodily attitudes. The hope that this approach may successfully be pursued does not seem unwarranted to us. ${ }^{24}$

The attitudinal theory we have outlined here avoids the difficulties with which both the judgment and the perceptual theories find themselves confronted. Like the perceptual theory, the attitudinal theory maintains that the phenomenology of emotions is essential to the way in which they relate to values. However, the two theories part company to the extent that the latter understands the relation to values in terms of distinct types of emotional attitudes. In other words, it denies that values need to be represented by emotions in order to feature into their correctness conditions. This is why the theory avoids many undesirable consequences we have had the opportunity to discuss. Within the specific brand of attitudinal theory defended here, the distinct evaluative correctness conditions of different emotion types trace back to distinctive types of felt bodily attitudes. As is the case for other attitudes, the formal objects of the emotions do not need to feature in their content. For that reason, we do not have to end up claiming that emotions presuppose the mastery of complex evaluative concepts, or that they are subtended by mysterious quasi-perceptual relations to values: the sense in which they relate to the latter traces back to the nature of the relevant attitudes which have nothing especially demanding or mysterious about them. ${ }^{25}$

\section{References}

Bermudez, J. L. (1998). The Paradox of Self-Consciousness (Cambridge, MA: MIT Press).

Brady, M. S. (2007). "Recalcitrant Emotions and Visual Illusions." American Philosophical Quarterly 44(3): 273-84.

Brady, M. S. (2009). “The Irrationality of Recalcitrant Emotions." Philosophical Studies 145(3): 413-30.

Brewer, B. (2002). Perception and Reason (Oxford: Clarendon Press).

Claparède, E. (1928). "Feelings and Emotions." In Feelings and Emotions: The Wittenberg Symposium, ed. M. L. Reymert (Worcester: Clark University Press), 124-39.

Colombetti, G. (2005). “Appraising Valence." Journal of Consciousness Studies 12(8-10): 103-26.

${ }^{24}$ The number of different profiles of systematic physiological changes susceptible to being distinctively felt is still an open empirical question, yet there are reasons to be optimistic (see e.g. Scherer 2009).

${ }_{25}$ We are grateful to Sabine Roeser, Cain Todd, and Michele Ombrato for their comments on a previous version of this chapter. We acknowledge the support of the SNSF-sponsored Swiss National Centre for Competence in Research (NCCR) in Affective Sciences. 
Crane, T. (1992). “The Nonconceptual Content of Experience." In The Contents of Experience: Essays on Perception, ed. T. Crane (Cambridge: Cambridge University Press), 136-57.

Creese, A. and Deonna, J. (2006). "Les Liaisons Dangereuses or How Not to Construe Nonconceptual Content." European Review of Philosophy 6: 101-15.

Damasio, A. (2000). The Feeling of What Happens: Body and Emotion in the Making of Consciousness (New York: Harcourt Brace).

D'Arms, J. and Jacobson, D. (2000). "The Moralistic Fallacy: On the 'Appropriateness' of Emotions." Philosophy and Phenomenological Research 61(1): 65-90.

de Sousa, R. (1987). The Rationality of Emotions (Cambridge, MA: MIT Press).

Deigh, J. (1994). "Cognitivism in the Theory of Emotion." Ethics 104(4): 824-54.

Deonna, J. A. (2006). “Emotion, Perception, and Perspective." Dialectica 60(1): 29-46.

Deonna, J. A. and Teroni, F. (2008). Qu'est-ce qu'une émotion (Paris: Vrin).

Deonna, J. A. and Teroni, F. (2012). The Emotions: A Philosophical Introduction (London and New York: Routledge).

Deonna, J. A. and Teroni, F. (forthcoming). "Emotions as Attitudes.” Dialectica.

Döring, S. (2007). "Seeing What to Do: Affective Perception and Rational Motivation." Dialectica 61(3):363-94.

Döring, S. (2008). "Conflict Without Contradiction.” In Epistemology and Emotions, ed. G. Brun, U. Doguoglu, and D. Kuenzle (Aldershot: Ashgate), 83-104.

Dretske, F. (2006). “Perception Without Awareness.” In Perceptual Experience, ed. T. S. Gendler and J. Hawthorne (Oxford: Clarendon Press), 147-80.

Goldie, P. (2004). "Emotion, Feeling, and Knowledge of the World." In Thinking About Feeling: Contemporary Philosophers on Emotions, ed. R. Solomon (New York: Oxford University Press), 91-106.

Greenspan, P. S. (1988). Emotions and Reason (New York: Routledge).

Gunther, Y. H. (2004). "Emotion and Force." In Essays on Nonconceptual Content, ed. Y. H. Gunter (Cambridge, MA: MIT Press), 279-88.

Helm, B. (2001). Emotional Reason: Deliberation, Motivation, and the Nature of Value (New York: Cambridge University Press).

Herzberg, L. A. (2012). “To Blend or to Compose: A Debate about Emotion Structure.” In Dynamicity in Emotion Concepts, ed. P. Wilson (Frankfurt: Peter Lang), 73-94.

Kenny, A. (1963). Action, Emotion and Will (London: Routledge).

McDowell, J. (1994). Mind and World (Cambridge, MA: Harvard University Press).

Mulligan, K. (1998). “From Appropriate Emotions to Values.” The Monist 81(1): 161-88.

Mulligan, K. (1999). "Perception, Particulars and Predicates." In Consciousness and Intentionality: Models and Modalities of Attribution, ed. D. Fisette. The Western Ontario Series in Philosophy of Science, Vol. 62 (Dordrecht: Kluwer), 163-94.

Nussbaum, M. (1994). The Therapy of Desire: Theory and Practice in Hellenistic Ethics (Princeton, NJ: Princeton University Press).

Prinz, J. (2004). Gut Reactions: A Perceptual Theory of Emotion (New York: Oxford University Press).

Roberts, R. (1988). “What an Emotion Is: A Sketch." Philosophical Review 97(2): 183-209.

Roberts, R. (2003). Emotion: An Essay in Aid of Moral Psychology (New York: Cambridge University Press). 
Scherer, K. R. (2009). "The Dynamic Architecture of Emotion: Evidence for the Component Model Process." Cognition and Emotion 23(7): 1307-51.

Solomon, R. (1988). “On Emotions as Judgments." American Philosophical Quarterly 25(2): 183-91.

Sturgeon, S. (2000). Matters of Mind: Consciousness, Reason and Nature (London: Routledge).

Tappolet, C. (2000). Emotions et valeurs (Paris: Presses Universitaires de France).

Tappolet, C. (2012). “Emotions, Perceptions, and Emotional Illusions." In Perceptual Illusions: Philosophical and Psychological Essays, ed. C. Calabi (Basingstoke: Palgrave Macmillan), 205-22.

Tappolet, C. (forthcoming). Emotions, Values, and Agency (New York: Oxford University Press). Teroni, F. (2007). “Emotions and Formal Objects.” Dialectica 61(3): 395-415.

Teroni, F. (2011). "Plus ou moins: émotions et valence." In Les ombres de l'âme: penser les émotions négatives, ed. C. Tappolet, F. Teroni, and A. Konzelmann Ziv (Geneva: Markus Haller Editions), 21-36. 